\title{
Chromatin Immunoprecipitation with Fixed Animal Tissues and Preparation for High-Throughput Sequencing
}

\author{
Justin L. Cotney ${ }^{1}$ and James P. Noonan \\ Department of Genetics, Yale University School of Medicine, New Haven, Connecticut 06520
}

Chromatin immunoprecipitation coupled with high-throughput sequencing (ChIP-Seq) is a powerful method used to identify genome-wide binding patterns of transcription factors and distribution of various histone modifications associated with different chromatin states. In most published studies, ChIP-Seq has been performed on cultured cells grown under controlled conditions, allowing generation of large amounts of material in a homogeneous biological state. Although such studies have provided great insight into the dynamic landscapes of animal genomes, they do not allow the examination of transcription factor binding and chromatin states in adult tissues, developing embryonic structures, or tumors. Such knowledge is critical to understanding the information required to create and maintain a complex biological tissue and to identify noncoding regions of the genome directly involved in tissues affected by complex diseases such as autism. Studying these tissue types with ChIPSeq can be challenging due to the limited availability of tissues and the lack of complex biological states able to be achieved in culture. These inherent differences require alterations of standard cross-linking and chromatin extraction typically used in cell culture. Here we describe a general approach for using small amounts of animal tissue to perform ChIP-Seq directed at histone modifications and transcription factors. Tissue is homogenized before treatment with formaldehyde to ensure proper crosslinking, and a two-step nuclear isolation is performed to increase extraction of soluble chromatin. Small amounts of soluble chromatin are then used for immunoprecipitation (IP) and prepared for multiplexed high-throughput sequencing.

It is essential that you consult the appropriate Material Safety Data Sheets and your institution's Environmental Health and Safety Office for proper handling of equipment and hazardous materials used in this protocol.

RECIPES: Please see the end of this protocol for recipes indicated by $<R>$. Additional recipes can be found online at http://cshprotocols.cshlp.org/site/recipes.

Reagents

When applicable, buffers can be prepared at a $2 \times$ concentration to allow for addition of various inhibitors and different concentrations of sodium dodecyl sulfate (SDS).

Agarose gel (1\% agarose)

Prepare in $1 \times T A E$ with $0.2 \mu \mathrm{g} / \mathrm{mL}$ ethidium bromide.

Antibodies to protein of interest

Many suppliers offer "ChIP-grade" versions of their antibodies that have high concentrations ( $1 \mathrm{mg} / \mathrm{mL})$. The use of more dilute antibodies or those not affinity-purified is not recommended.

\footnotetext{
${ }^{1}$ Correspondence: justin.cotney@yale.edu

(c) 2015 Cold Spring Harbor Laboratory Press

Cite this protocol as Cold Spring Harb Protoc; doi:10.1101/pdb.prot084848
} 
J.L. Cotney and J.P. Noonan

Bead binding buffer $<\mathrm{R}>$

Cell lysis buffer for ChIP-Seq $<\mathrm{R}>$

ChIP-Seq dilution buffer $<\mathrm{R}>$

ChIP-Seq elution buffer $<\mathrm{R}>$

ChIP-Seq nuclear lysis buffer (see Step 24$)<\mathrm{R}>$

ChIP-Seq wash buffer $<\mathrm{R}>$

DNA loading dye (e.g., Orange Loading Dye [NEB B7022S])

Standard DNA loading dye recipes call for bromophenol blue, which migrates at the same rate as the desired chromatin fragments. We recommend using a loading dye that migrates more quickly through the gel (e.g., Orange G).

Ethidium bromide $(10 \mathrm{mg} / \mathrm{mL})$

Formaldehyde (37\%)

Glycine $(2.5 \mathrm{M})$

Liquid nitrogen (optional; see Steps 18 and 38)

Magnetic Protein G or Protein A beads (Dynabeads from Invitrogen/Life Technologies)

Phosphate buffered saline (PBS), prepared from powder (Sigma-Aldrich P5368) and prechilled to $4^{\circ} \mathrm{C}$ before use

Proteinase K $(20 \mathrm{mg} / \mathrm{mL})$

QIAquick PCR purification kit (Qiagen)

qPCR primers

Properly designed qPCRs are critical for assessing the quality of each ChIP. Primers should flank a known binding site for a transcription factor or region known to contain high levels of a particular histone modification. We typically design qPCR primers with Primer3Plus (http://www.bioinformatics.nl/cgi-bin/primer3plus/primer3plus.cgi/). Amplicon length should be set between 85 and $150 \mathrm{bp}$. Use an optimal primer size of $20 \pm 2 \mathrm{nt}$, an optimal melting temperature of $60^{\circ} \mathrm{C} \pm 2^{\circ} \mathrm{C}$ with no more than $3^{\circ} \mathrm{C}$ difference in melting temps between primers, and an optimal GC content of $50 \% \pm 10 \%$. All primers should be tested with a dilution series of genomic DNA to confirm a single product and good efficiency over a range of template concentrations.

Quant-iT PicoGreen dsDNA Assay Kit (Invitrogen/Life Technologies)

RNase A (10 mg/mL, DNase-free)

Sodium acetate $(3 \mathrm{M}, \mathrm{pH} 5.2)$

Sodium butyrate (1 M) (optional; see Step 19)

Sodium dodecyl sulfate (SDS) (20\%)

SYBR Green qPCR Master Mix (Invitrogen/Life Technologies)

$\mathrm{TAE}<\mathrm{R}>$

TE buffer for ChIP-Seq $<\mathrm{R}>$

Tissue to be examined

This protocol is optimized for small amounts of fresh or frozen tissue. One IP is generally performed with $10^{4}$ to $10^{5}$ cells. This amount of material can be obtained from one litter of E10.5 mouse limb buds (i.e., 8-10 forelimb buds), five to ten 20- $\mu \mathrm{m}$ thick sections of frozen tumor block, or 1-5 mg of fresh tissue. However, the protocol has successfully been used for tissue amounts ranging from 25 E11.5 mouse limb buds ( 1 million cells) to two E33 human limb buds ( 50,000 cells). If substantially more tissue is used, further dissection of the tissue may be required or empirical optimization of the protocol for increased cell number may be needed. Performing a ChIP on previously studied material in tandem may be necessary to confirm successful IP.

\section{Equipment}

Disposable plastic pestles (Kontes) or Polytron homogenizer with 3.5-mm tip (Kinematica)

Dounce homogenizer with tight and loose pestles $(2 \mathrm{~mL}$; Kontes)

Prechill before starting protocol.

Fluorospectrometer (NanoDrop 3300)

Other sensitive double-strand DNA detection methods and detectors are available such as the Qubit system from Invitrogen.

Gel electrophoresis apparatus 


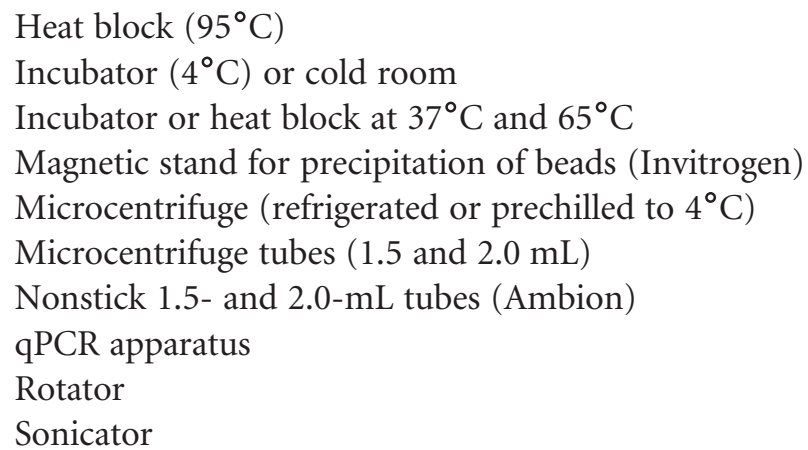

We use a Misonix 54000 sonicator with attached 431A cup horn. A chilled Fisher Isotemp 3006D recirculator pump continuously cycles cold water through the cup horn to dissipate any heat generated during sonication. Alternatively, ice water can be kept in the cup horn and changed frequently.

Thermomixer (Eppendorf)

\section{METHOD}

\section{Preparation of Antibody Beads}

This portion of the protocol requires $\sim 30$ min followed by an overnight incubation. It can be performed a day in advance of chromatin extraction (or at any point if frozen chromatin aliquots are to be used).

1. Resuspend magnetic Protein G (or Protein A) beads on a rotator for $5 \mathrm{~min}$ at room temperature.

2. For each IP to be performed, aliquot $50 \mu \mathrm{L}$ of beads into a microcentrifuge tube. If several IPs will be performed using the same antibody, combine up to eight reactions worth of beads in a single 2-mL tube.

3. Wash the beads with $1 \mathrm{~mL}$ of bead binding buffer by resuspending the beads, placing the tubes on the magnetic stand for $1 \mathrm{~min}$, and removing the bead binding buffer. Repeat. If combining multiple aliquots of beads in a single tube, increase number of washes to five.

4. Resuspend the beads in $200 \mu \mathrm{L}$ of bead binding buffer per IP. If performing eight IPs, resuspend the beads in $1.6 \mathrm{~mL}$ of bead binding buffer in a 2-mL tube.

5. Add up to $10 \mu \mathrm{g}$ of the desired antibody per IP. The amount of antibody will vary considerably and will need to be empirically tested. Scale accordingly as above for multiple aliquots of beads.

6. Incubate the beads and antibody on the rotator overnight at $4^{\circ} \mathrm{C}$.

7. Wash the beads twice with $1 \mathrm{~mL}$ of bead-binding buffer and then twice with $1 \mathrm{~mL}$ of ChIP-Seq dilution buffer. Perform each wash by placing the tubes on the magnetic stand for $1 \mathrm{~min}$ and then removing the supernatant.

Increase number of washes to five bead-binding buffer washes and five ChIP-Seq dilution buffer washes if multiple reactions were combined above.

8. Resuspend the beads in $50 \mu \mathrm{L}$ of ChIP-Seq dilution buffer per IP to be performed.

9. Store the beads at $4^{\circ} \mathrm{C}$ until the chromatin is prepared.

\section{Tissue Harvest and Cross-Linking}

This procedure takes $\sim 1$ h, not including any time necessary to harvest or dissect tissue.

10. Transfer fresh or frozen tissue to a clean $1.5-\mathrm{mL}$ tube containing $250 \mu \mathrm{L}$ of ice-cold PBS.

11. Briefly homogenize the tissue by hand to yield chunks $0.5 \mathrm{~mm}^{3}$ or smaller. Use a disposable plastic pestle or a handheld Polytron homogenizer fitted with 3.5-mm tip. 
J.L. Cotney and J.P. Noonan

12. Add ice-cold PBS to a final volume of $1 \mathrm{~mL}$.

13. Cross-link the tissue by adding $27 \mu \mathrm{L}$ of $37 \%$ formaldehyde (1\% final) to each tube and immediately invert the tube several times.

14. Incubate the tube on the rotator at room temperature for $15 \mathrm{~min}$.

15. Quench the cross-linking by adding $67 \mu \mathrm{L}$ of $2.5 \mathrm{~m}$ glycine ( $150 \mathrm{~mm}$ final) and incubate the tube on the rotator at room temperature for an additional $10 \mathrm{~min}$.

16. Harvest the tissue by centrifugation at $2000 \mathrm{~g}$ for $10 \mathrm{~min}$ at $4^{\circ} \mathrm{C}$.

17. Remove the supernatant and add $1 \mathrm{~mL}$ of ice-cold PBS. Flick the tube with your finger several times to dislodge the pellet.

18. Harvest the tissue by centrifugation at $2000 \mathrm{~g}$ for $10 \mathrm{~min}$ at $4^{\circ} \mathrm{C}$ and discard the supernatant. Flash freeze the tissue pellet in liquid nitrogen and store at $-80^{\circ} \mathrm{C}$.

Alternatively, proceed to Step 19 without freezing.

\section{Chromatin Extraction and Shearing}

This procedure requires $\sim 5 \mathrm{~h}$.

19. Resuspend the frozen cross-linked tissue pellet in six volumes of ice-cold cell lysis buffer for ChIP-Seq. Use the markings on the 1.5-mL tube to provide an estimate of the pellet volume. If the pellet is very small, resuspend it in $300 \mu \mathrm{L}$ of cell lysis buffer.

Cell pellets at this stage will frequently adhere to the insides of pipette tips. It may be necessary to resuspend the pellet by flicking the tube several times instead of by pipetting. If the tissue remains in large chunks, homogenize it in a prechilled Dounce homogenizer with a loose pestle (pestle A) five to 10 times.

20. Incubate the tube on ice for $20 \mathrm{~min}$.

This incubation period allows for swelling of cells to allow for mechanical lysis while keeping nuclei intact.

21. Transfer the tissue suspension to a prechilled Dounce homogenizer and homogenize with 30-40 strokes with the tight pestle (pestle B).

22. Transfer the homogenate to a fresh nonstick 1.5-mL tube, rinse the Dounce homogenizer with $500 \mu \mathrm{L}$ of cell lysis buffer, and combine.

23. Harvest the nuclei by centrifugation at $2000 \mathrm{~g}$ for $5 \mathrm{~min}$ at $4^{\circ} \mathrm{C}$.

The pellet will be not be as tight against the tube as the original cell pellet and will be mostly white.

24. Remove the supernatant and resuspend the nuclei in five volumes of ice-cold ChIP-Seq nuclear lysis buffer (based on the volume of the original cell pellet in Step 19).

The ChIP-Seq nuclear lysis buffer contains $0.2 \%$ SDS to aid in the lysis of nuclei. Some tissues such as brain samples require SDS concentrations of up to $0.5 \%$; this will need to be empirically determined. High concentrations of SDS can inhibit antibody-binding downstream and will require further dilution or dialysis detailed below before using in IPs.

25. Incubate the tube on ice for $20 \mathrm{~min}$.

26. Take a $5-\mu \mathrm{L}$ aliquot from each sample and dilute it with $15 \mu \mathrm{L}$ of TE for an analytical gel.

Store the aliquots on ice until required. This sample is to confirm that the chromatin was intact before isolation.

27. Place the tube in the sonicator bath set at $2^{\circ} \mathrm{C}$.

In our hands, sonicating a volume of $300 \mu \mathrm{L}$ per tube with the Misonix 431A cup horn has performed very consistently, so we advise dividing larger samples into multiple tubes for sonication. Place at least two and up to eight tubes in the tube holder in the sonicator.

28. Adjust the water level so that the tubes just touch the surface of the cup horn.

29. Sonicate the samples at amplitude 20 with 10 -sec pulses and 10 -sec rest for a total sonication time of $30 \mathrm{~min}$.

30. Remove the samples from the sonicator and store on ice. 


\section{Binding of Antibody to Target Antigen}

This procedure requires $\sim 10$ min followed by an overnight incubation.

41. Dilute 30-50 $\mu$ g of chromatin from Step 38 with ChIP-Seq dilution buffer in a fresh nonstick tube to reduce the SDS concentration $<0.1 \%$ and achieve a final volume of $450 \mu \mathrm{L}$.

The amount of chromatin to be used will be highly antibody-and target-dependent and must be determined empirically, with 1-50 $\mu$ g as a general range. Histones are highly abundant and widespread across the genome, whereas transcription factors are much less abundant and have specific binding sites.

42. Reserve $5 \%-10 \%$ of diluted chromatin as an input sample and store at $4^{\circ} \mathrm{C}$.

Input must be reserved to assess enrichment via $q P C R$ and to provide a necessary control for comparing sequence data to identify true binding sites or regions of enrichment.

43. Add $50 \mu \mathrm{L}$ of the prepared antibody beads from Step 9 to each tube of diluted chromatin.

44. Incubate tube on the rotator overnight at $4^{\circ} \mathrm{C}$.

IP of Chromatin

This procedure requires $\sim 2 \mathrm{~h}$ followed by an overnight incubation. Perform all washes and incubations in a cold room.

45. Remove the tube containing chromatin and the antibody beads from the rotator, place it on the magnet, and let it stand for $1 \mathrm{~min}$.

46. Remove the supernatant and transfer it to a fresh tube if required for additional IPs or troubleshooting.

47. Wash the beads from each IP with $1 \mathrm{~mL}$ of ChIP-Seq wash buffer by pipetting the beads up and down or inverting the tube several times to mix.

48. Place the tube on the rotator and incubate for $3 \mathrm{~min}$.

49. Place the tube on the magnet to precipitate the beads and remove supernatant.

50. Repeat Steps 47 through 49 for a total of eight washes.

51. Perform one wash with $1 \mathrm{~mL}$ of TE. Remove the supernatant. 
J.L. Cotney and J.P. Noonan

52. Resuspend the beads in $85 \mu \mathrm{L}$ of ChIP-Seq elution buffer.

53. Elute the chromatin at $65^{\circ} \mathrm{C}$ with agitation on the thermomixer for $10 \mathrm{~min}$.

The beads will settle if not agitated frequently. If a thermomixer is not available, mix the beads by flicking the tubes with your finger every 2 min.

54. Place the tube on the magnet and transfer the eluate to a fresh nonstick tube.

55. Repeat elution with a second volume of $85 \mu \mathrm{L}$ of ChIP-Seq elution buffer and combine eluates.

56. Incubate the combined eluates at $65^{\circ} \mathrm{C}$ overnight to reverse the cross-links.

57. For each input control (see Step 42), add ChIP-Seq elution buffer to a final volume of $170 \mu \mathrm{L}$ and incubate overnight at $65^{\circ} \mathrm{C}$.

\section{Purification of Chromatin}

This procedure requires $\sim 4 \mathrm{~h}$.

58. Add $10 \mu \mathrm{g}$ of RNase A to each tube of input and IP chromatin and incubate for $1 \mathrm{~h}$ at $37^{\circ} \mathrm{C}$.

59. Add $200 \mu \mathrm{g}$ proteinase $\mathrm{K}$ diluted in $120 \mu \mathrm{L}$ TE to each tube and incubate for $2 \mathrm{~h}$ at $65^{\circ} \mathrm{C}$.

60. Transfer each reaction to a 2-mL nonstick tube and add five volumes of PBI from the QIAquick PCR Purification Kit. Add $10 \mu \mathrm{L}$ of $3 \mathrm{~m}$ sodium acetate to adjust the $\mathrm{pH}$ and generate a bright yellow color.

Phenol:chloroform extraction and ethanol precipitation of DNA can be substituted here if preferred. However, depending on the amount of chromatin obtained, a significant volume of sample may be required for subsequent high-throughput sequencing library generation. Phenol carryover may inhibit initial end repair steps and result in low-quality libraries.

61. Follow the QIAquick PCR Purification Kit instructions and elute the DNA with $50 \mu \mathrm{L}$ of EB into a fresh nonstick 1.5-mL tube.

$E B$ can be prewarmed to $50^{\circ} \mathrm{C}$ before elution to maximize recovery.

62. Quantify the DNA recovered by IP and in the input sample with PicoGreen and a Fluorospectometer.

63. Dilute a portion of the ChIP and input samples with $\mathrm{dH}_{2} \mathrm{O}$ to the same concentration in nonstick tubes $(50-500 \mathrm{pg} / \mu \mathrm{L})$.

Analysis by qPCR

64. Analyze target regions by qPCR using the following reaction:

$\begin{array}{lr}\text { Template DNA from either input or IP } & 1 \mu \mathrm{L} \\ \text { Primer mix (forward and reverse primers premixed at } 10 \mu \mathrm{M} \text { each) } & 2.5 \mu \mathrm{L} \\ 2 \times \text { SYBR Green qPCR Master Mix } & 10 \mu \mathrm{L} \\ \mathrm{dH}_{2} \mathrm{O} & \text { to } 20 \mu \mathrm{L}\end{array}$

65. Run the samples on the qPCR machine with standard conditions for SYBR Green. Adjust conditions as your instrument and reagents require.

i. Melt the template for $10 \mathrm{~min}$ at $95^{\circ} \mathrm{C}$.

ii. Amplify the target by performing 40 cycles of $15 \mathrm{sec}$ at $95^{\circ} \mathrm{C}$ and $1 \mathrm{~min}$ at $60^{\circ} \mathrm{C}$, measuring the fluorescence after each cycle.

iii. Examine the melting curve to ensure that a single product is made in each reaction.

A good reference for performing qPCR is Bustin et al. (2009).

66. Measure enrichment by comparing Ct values between input and ChIP reactions.

Depending on the type of factor being immunoprecipitated, fold enrichments versus input can vary considerably. For histone modifications, four- to 16-fold enrichments are acceptable. For transcription factors and other sequence specific DNA-binding proteins, enrichments would be expected to be quite higher, up to 60-fold. 
Preparation of Samples for High-Throughput Sequencing

67. Dilute $10 \mathrm{ng}$ of ChIP or input DNA with $\mathrm{dH}_{2} \mathrm{O}$ to a final volume of $30 \mu \mathrm{L}$ in a fresh nonstick tube for high-throughput sequencing library preparation.

Both ChIP and input samples must be sequenced to identify real binding peaks or enriched regions from more abundant open chromatin in the input sample.

68. Follow the manufacturer's instructions for preparing libraries with a kit.

We routinely use kits from NEB (e.g., E6240) for sequencing on Illumina instruments. Many library prep kits for different sequencing instruments are now commercially available.

\section{TROUBLESHOOTING}

Problem (Step 36): Chromatin is not successfully sheared to fragments between 200 and $500 \mathrm{bp}$.

Solution: Sonication (Step 29) is the most critical step to a successful ChIP. Fragments longer than $500 \mathrm{bp}$ may result in very wide peaks and a high degree of genomic background; in contrast, oversonication can destroy protein complexes and result in no IP. For each new tissue type, sonication must be optimized to achieve consistent levels of chromatin shearing. Amplitude 20 is a good general starting point, but can be increased as needed based on the shearing level observed in the agarose gel. Depending on the number of tubes tested in the 431A cup horn, the amplitude should be adjusted to obtain $\sim 12$ to $15 \mathrm{~W}$ output per tube during operation. This level is sufficient to properly shear most samples, but more difficult samples such as fibrous tumors will require higher amplitudes and a longer processing time. During optimization stages, take 5$\mu \mathrm{L}$ aliquots (dilute with $15 \mu \mathrm{L}$ of $\mathrm{TE}$ ) at regular intervals to determine the proper length of sonication time.

\section{RELATED INFORMATION}

ChIP-Seq has been used extensively to study genome-wide histone modification profiles and transcription factor occupancy in cultured human and murine cells (Neph et al. 2012; Thurman et al. 2012; Shen et al. 2012). Few studies have used tissue for ChIP-Seq and those that have reported the use of large amounts of tissue and milligram quantities of soluble chromatin for a single experiment (Visel et al. 2009; Blow et al. 2010). Use of this protocol to identify active enhancers marked with histone $\mathrm{H} 3$ lysine 27 acetylation (H3K27ac) in early murine and primate limb development is described in Cotney et al. (2013).

\section{Bead-Binding Buffer}

Phosphate-buffered saline (PBS)

Tween $20(0.2 \%)$

Dissolve one pouch of powdered PBS (Sigma-Aldrich P5368) in $1 \mathrm{~L}$ of $\mathrm{dH}_{2} \mathrm{O}$, and sterilize by autoclaving. Add Tween 20 to a final concentration of $0.2 \%$, and filter-sterilize. Store for up to $1 \mathrm{yr}$ at $4^{\circ} \mathrm{C}$.

Cell Lysis Buffer for ChIP-Seq

$50 \mathrm{~mm}$ Tris ( $\mathrm{pH} 8.0)$

$140 \mathrm{~mm} \mathrm{NaCl}$

$1 \mathrm{~mm}$ EDTA 
J.L. Cotney and J.P. Noonan

$10 \%$ glycerol

$0.5 \%$ NP-40

$0.25 \%$ Triton $\mathrm{X}-100$

Filter-sterilize. Store for up to $1 \mathrm{yr}$ at $4^{\circ} \mathrm{C}$. Add one protease inhibitor tablet or $2 \mathrm{~mL}$ of $25 \times$ inhibitor stock solution as directed by the manufacturer (cOmplete EDTA-Free; Roche) per $50 \mathrm{~mL}$ of buffer immediately before use. In addition, if immunoprecipitating with an antibody against the histone modification $\mathrm{H} 3 \mathrm{~K} 27 \mathrm{ac}$, include the histone deacetylase inhibitor sodium butyrate at a final concentration of $5 \mathrm{~mm}$. Other inhibitors are generally not necessary when immunoprecipitating transcription factors but should be considered when using antibodies against posttranslational covalent modifications.

\section{ChIP-Seq Dilution Buffer}

$0.01 \%$ SDS

$1.1 \%$ Triton $\mathrm{X}-100$

$1.2 \mathrm{~mm}$ EDTA

16.7 mм Tris $(\mathrm{pH} 8.1)$

$167 \mathrm{~mm} \mathrm{NaCl}$

Filter-sterilize. Store for up to $1 \mathrm{yr}$ at $4^{\circ} \mathrm{C}$. Add one protease inhibitor tablet or $2 \mathrm{~mL}$ of $25 \times$ inhibitor stock solution as directed by the manufacturer (cOmplete EDTA-Free; Roche) per $50 \mathrm{~mL}$ of buffer immediately before use.

\section{ChIP-Seq Elution Buffer}

$50 \mathrm{~mm}$ Tris $(\mathrm{pH} 8.0)$

$10 \mathrm{~mm}$ EDTA

$1 \%$ SDS

Filter-sterilize. Store for up to $1 \mathrm{yr}$ at $4^{\circ} \mathrm{C}$.

ChIP-Seq Nuclear Lysis Buffer

$10 \mathrm{~mm}$ Tris $(\mathrm{pH} 8.0)$

$1 \mathrm{mM}$ EDTA

$0.5 \mathrm{~mm}$ EGTA

$0.2 \%$ SDS concentration can be increased to $(0.5 \%$ SDS as required)

Filter-sterilize. Store for up to $1 \mathrm{yr}$ at $4^{\circ} \mathrm{C}$. Add one protease inhibitor tablet or $2 \mathrm{~mL}$ of $25 \times$ inhibitor stock solution as directed by the manufacturer (cOmplete EDTA-Free; Roche) per $50 \mathrm{~mL}$ of buffer immediately before use.

\section{ChIP-Seq Wash Buffer}

$100 \mathrm{~mm}$ Tris $(\mathrm{pH} 8.0)$

$500 \mathrm{~mm} \mathrm{LiCl}$ (or $\mathrm{NaCl}$, for a lower-stringency wash)

$1 \%$ NP-40

$1 \%$ deoxycholic acid

Filter-sterilize. Store for up to $1 \mathrm{yr}$ at $4^{\circ} \mathrm{C}$. Add one protease inhibitor tablet or $2 \mathrm{~mL}$ of $25 \times$ inhibitor stock solution as directed by the manufacturer (cOmplete EDTA-Free; Roche) per $50 \mathrm{~mL}$ of buffer immediately before use.

\section{$T A E$}

Prepare a $50 \times$ stock solution in $1 \mathrm{~L}$ of $\mathrm{H}_{2} \mathrm{O}$ : $242 \mathrm{~g}$ of Tris base 
$57.1 \mathrm{~mL}$ of acetic acid (glacial)

$100 \mathrm{~mL}$ of $0.5 \mathrm{~m}$ EDTA (pH 8.0)

The $1 \times$ working solution is $40 \mathrm{~mm}$ Tris-acetate/ $1 \mathrm{~mm}$ EDTA.

TE Buffer for ChIP-Seq

$50 \mathrm{~mm}$ Tris $(\mathrm{pH} 8.0)$

$10 \mathrm{~mm}$ EDTA

Filter-sterilize or autoclave. Store for up to $1 \mathrm{yr}$ at $4^{\circ} \mathrm{C}$.

\section{REFERENCES}

Bustin SA, Benes V, Garson JA, Hellemans J, Huggett J, Kubista M, Mueller R, Nolan T, Pfaffl MW, Shipley GL, et al. 2009. The MIQE guidelines: Minimum information for publication of quantitative real-time PCR experiments. Clin Chem 55: 611-622.

Blow MJ, McCulley DJ, Li Z, Zhang T, Akiyama JA, Holt A, Plajzer-Frick I, Shoukry M, Wright C, Chen F, et al. 2010. ChIP-Seq identification of weakly conserved heart enhancers. Nat Genetics 42: 806-810.

Cotney J, Leng J, Yin J, Reilly SK, Demare LE, Emera D, Ayoub AE, Rakic P, Noonan JP. 2013. The evolution of lineage-specific regulatory activities in the human embryonic limb. Cell 154: 185-196.

Neph S, Vierstra J, Stergachis AB, Reynolds AP, Haugen E, Vernot B, Thurman RE, John S, Sandstrom R, Johnson AK, et al. 2012. An ex- pansive human regulatory lexicon encoded in transcription factor footprints. Nature 489: 83-90.

Shen Y, Yue F, McCleary DF, Ye Z, Edsall L, Kuan S, Wagner U, Dixon J, Lee L, Lobanenkov VV, et al. 2012. A map of the cis-regulatory sequences in the mouse genome. Nature 488: 116-120.

Thurman RE, Rynes E, Humbert R, Vierstra J, Maurano MT, Haugen E, Sheffield NC, Stergachis AB, Wang H, Vernot B, et al. 2012. The accessible chromatin landscape of the human genome. Nature 489: $75-82$.

Visel A, Blow MJ, Li Z, Zhang T, Akiyama JA, Holt A, Plajzer-Frick I, Shoukry M, Wright C, Chen F, et al. 2009. ChIP-seq accurately predicts tissue-specific activity of enhancers. Nature 457: 854-858. 


\title{
Chromatin Immunoprecipitation with Fixed Animal Tissues and Preparation for High-Throughput Sequencing
}

\author{
Justin L. Cotney and James P. Noonan
}

Cold Spring Harb Protoc; doi: 10.1101/pdb.prot084848

\begin{tabular}{cc}
$\begin{array}{c}\text { Email Alerting } \\
\text { Service }\end{array}$ & Receive free email alerts when new articles cite this article - click here. \\
\hline $\begin{array}{r}\text { Subject } \\
\text { Categories }\end{array}$ & $\begin{array}{c}\text { Browse articles on similar topics from Cold Spring Harbor Protocols. } \\
\text { Bioinformatics/Genomics, general (192 articles) } \\
\text { DNA:Protein Interactions (74 articles) } \\
\text { Genome Analysis (191 articles) } \\
\text { High-Throughput Analysis, general (155 articles) } \\
\text { Immunoprecipitation (75 articles) }\end{array}$ \\
\hline
\end{tabular}

